\title{
Review on Effect of Corrosion on Flexure, Shear and Torsional Strength of Reinforced Concrete Beam
}

\author{
Abhinav Chouhan ${ }^{1}$, Prof. Nikhil Pitale ${ }^{2}$ \\ ${ }^{1}$ Research Scholar, Department of Civil Engineering, G. H. Raisoni College of Engineering Nagpur, \\ Maharashtra India. \\ ${ }^{2}$ Assistant Professor Department of Civil Engineering, G.H. Raisoni College of Engineering, Nagpur, \\ Maharashtra, India
}

\begin{abstract}
With the increase in demand for construction materials, man has improved a lot in the construction techniques of structures. Reinforced concrete beams are normally designed as under reinforced to provide ductile behavior such as the tensile moment of resistance. In coastal environment reinforcement corrosion is an obvious cause of deterioration of concrete structure, which affects the durability and service of reinforced concrete structure. Structural stability is majorly influenced by strength of concrete. Torsional strength is a measure of the shear strength of concrete, in other words it is a measure of a resistance against failure in twisting. The main aim of this study is to analyze the flexural, shear \& torsional strength, experimentally; of corroded beams using Ordinary Portland cement. Accelerated corrosion technique was adopted to corrode the beam experimentally. We have used varying percentage of corrosion as $0 \%, 2.5 \%, 5 \%$ and $7.5 \%$. Change in strength of RC beams is studied for varying percentage of corrosion. Beam specimens are prepared using M20 grade concrete for OPC. Beam specimens casted are tested in UTM for flexure and shear. Specially prepared loading setup is used for torsional strength test.
\end{abstract}

Keywords : Concrete, Reinforcement, Accelerated Corrosion, Shear.

\section{INTRODUCTION}

Reinforced concrete (RC) is the foremost wide used building component due to its extensive accessibility. Reinforced materials are embedded within the concrete in such a way that the two materials resist the applied forces along. The compressive strength of concrete and the tensile strength of steel form a powerful bond to resist these stresses over a protracted span. Plain concrete is not appropriate for many constructions works, as a result of it cannot simply face up to the stresses generated by vibrations, wind, or alternative forces.
Its utilized in completely different engineering applications worldwide like buildings, bridges, dams, and newly as a foundation system for wind turbine towers. Because of the wide variety of reinforced concrete applications, RC structures are subjected to a range of different environmental exposures as well as marine, industrial, nuclear, and other extreme environments. The existing concrete structures may, perform unsatisfactorily due to a variety of reasons. Which causes poor performance of the structures under service loading, in the form of excessive deflections and cracking, or there could be inadequate ultimate strength. 


\section{LITERATURE REVIEW}

\section{Adheena Thomas, Afia S Hameed(2017) et.al} When the load was acting away from the resultant force from the shear center axis, combined action of bending and torsions occurs. The present investigation aims to study the combined action of flexure and torsion for which two beams are casted. The test set up is specially fabricated for applying combined torsion and bending. For the study, Crack pattern, load- deflection characteristics, torquetwist response have been taken of those specimens. Objective of study is to study the combined flexural and torsional behavior of RC beams experimentally.[1]

\section{Chhabirani Tudu(2012) et.al Fiber Reinforced} Polymer (FRP) as an external reinforcement is used extensively to deal with the strength requirements related to flexure and shear in structural systems. But the strengthening of members subjected to torsion is explored only recently. Torsion failure is an undesirable brittle form of failure which should be avoided specially in the earthquake prone areas. In the present work, the behavior and performance of rectangular reinforced concrete beams strengthened with externally bonded Glass Fiber Reinforced Polymer (GFRP) fabrics subjected to combined flexure and torsion is studied experimentally..[2]

\section{Suresh Bhalgamiya, Govind Tivadi, Mehul} Jethva(2018) et.al Concrete durability is an important design criterion, which must be assessed for every type of structure. Reinforcement corrosion has widely reported in literature over last two Decades. It is one of the major durability problems, mainly when rebar in concrete is exposed to the chloride either contributed from the concrete ingredients or penetrated from surrounding chloride bearing environment. Corrosion of steel in concrete is a slow process. Due to the protective nature of concrete, it takes a reasonably long time for initiation and progress. The assessment of causes and extent of corrosion is carried out using accelerated corrosion techniques..[3]

\section{Needa Marwan Lingga(2016) et.al Severe} premature deterioration has been reported in a large number of reinforced concrete (RC) structures in corrosive environments. Many concrete structures built in the past few decades are already showing signs of deterioration due to the corrosion of steel reinforcement. This premature deterioration can diminish structural integrity and safety of the structure. There are several options available for retrofitting the structural members of existing reinforced concrete (RC) structures. [4]

\section{Mohammad Rashidi, Hana Takhtfiroozeh(2016)} et.al Many structural elements in building and bridge construction are subjected to significant torsional moments that affect the design. A simple experiment for the evaluation of the torsional strength of reinforced concrete beams as a one of this structural elements is presented in this research. The objective of this experiments would be the role of transverse and longitudinal reinforcement on torsion strength. Four beam test samples has been tested with the same length and concrete mix design..[5]

\section{A. Aryanto \& Y. Shinohara(2012) et.al Bond is one} of the main keys to assess the performance of reinforced concrete $(\mathrm{RC})$ structure against seismic load. In this paper, the bond behavior including bond stress, crack propagation, crack spacing and tension stiffening of tension RC members was experimentally investigated under certain levels of corrosion of reinforcing steel. Seven cylindrical specimens having $19 \mathrm{~mm}$ bar diameter and 2.8 cover to bar diameter ratio were prepared and tested under simulated corrosive environment. The corrosion level was ranging from $0 \%$ to $4 \%$ in mass loss. In low 
level corrosion up to $1 \%$ of corrosion level, the bond stress increases causing a decrease in average crack spacing. For higher corrosion levels the decrease of average crack spacing is attributed to the decreasing of concrete tensile strength caused by cracks around corroded bar. A simple analytical formula has been proposed to predict the mean crack spacing of corroded tension members. [6]

\section{Naga Chaitanya , Vamsi Krishna(2014) et.al}

Reinforced concrete beams are normally designed as under reinforced to provide ductile behavior such as the tensile moment of resistance. In coastal environment reinforcement corrosion is an obvious cause of deterioration of concrete structure, which affects the durability and service of reinforced concrete structure. Structural stability is majorly influenced by strength of concrete. Flexural strength is a measure of the tensile strength of concrete, in other words it is a measure of a resistance against failure in bending. The main aim of this study is to analyze the strength, experimentally; of corroded beams using Ordinary Portland cement. Accelerated corrosion technique was adopted to corrode the beam experimentally. The corrosion was measured using Applied Corrosion monitoring instrument. Beam specimens are prepared using M20 grade concrete for OPC. Beam specimens casted are tested as vertical cantilever beam in specially prepared loading setup and load deflection behavior is studied.[7]

8. Khaldoun N. Rahal(2011) et.al A simple method for predicting the ultimate strength and mode of failure of reinforced concrete beams subjected to pure torsion is presented. This method is an extension of a recently developed method for predicting the strength of membrane elements subjected to pure shear that was also applied to beams subjected to combined shearing forces, bending moments, and axial loads. [8]
9. Akshatha Shetty, Katta Venkataramana and K. S. Babu Narayan(2014) et.al Corrosion is one of the main causes affecting durability of structures. Corrosion effects on structures cannot be ignored and replaced. To understand the performance of structures there is a need to study the rate at which different corrosion levels occur. Hence the present investigation has been taken up to study the behavior of NBS (National Bureau of Standard) beam specimens made up of Ordinary Portland Cement (OPC) and Portland Pozzolana Cement (PPC) concrete matrix were subjected to accelerated corrosion for different corrosion levels of $2.5 \%$ to $10 \%$ at $2.5 \%$ interval. Results are compared with those for control beam specimen. It is observed that bond stress value decreases with the increase in corrosion levels. Also corrosion leads to the decline of load carrying capacity.[9]

\section{Ahmed K El-Sayed, Raja R Hussain, Ahmed B} Shuraim(2016) et.al The effect of stirrups damage due to corrosion on the shear strength and behavior of reinforced concrete beams was experimentally investigated. A total of fourteen full-scale reinforced concrete beams were constructed and tested under four-point bending up to failure. The test beams were $200 \mathrm{~mm}$ wide, $350 \mathrm{~mm}$ deep, and $2800 \mathrm{~mm}$ long. The reinforcing stirrups of nine of the beams were subjected to accelerated corrosion prior to structural testing. The test variables were the corrosion damage level, spacing of stirrups, and shear span to depth ratio. The beams were tested under shear span to depth ratio of 2 or 1 representing short or deep members. The test results indicated that the corroded beams exhibited degradation in stiffness and shear strength in comparison to the uncorroded control specimens. This degradation appeared to increase as the corrosion level increases and as stirrup spacing as well as shear span to depth ratio decreases..[10] 
11. Shamsad Ahmad(2009) et.al Corrosion of steel in concrete is a slow process. Due to the protective nature of concrete, it takes a reasonably long time for initiation and progress of reinforcement corrosion even in the case of severe corrosive exposure conditions. It is difficult to achieve a significant degree of reinforcement corrosion in a limited duration available for performing research studies evaluating (i) the loss of bond and loss of loadbearing capacity of corroding reinforced concrete members, (ii) the effect of mineral admixtures in reducing reinforcement corrosion, (iii) the performance of coated or alloyed reinforcing bars against reinforcement corrosion, and (iv) the effectiveness of electrochemical techniques applied for the prevention of reinforcement corrosion. For this reason, various techniques for inducing accelerated corrosion of steel in concrete are used by the researchers. In this paper, an attempt has been made to firstly describe the impressed current technique commonly used for accelerating reinforcement corrosion in small- as well as large-sized concrete specimens in the light of state-of-the art information available in the literature..[11]

\section{Ashutosh S.Trivedi, R.P.Sharma, Sarvesh K Jain,} S.S.Bhadauria, Abhishek Tiwari(2017) et.al This paper examines various aspects of corrosion of reinforcement embedded in concrete by various factors like moisture, permeability $\mathrm{pH}$ and temperature etc and also their corrosion control methods.[12]

13. P. R. Wankhede et.al experimentally studied that the exploration finishes up the examination on the impact of fly fiery debris on the properties of concrete for ostensible blend of M25 evaluation of cement. Droop loss of solid increments with increment in w/c proportion of concrete.[13]

\section{CONCLUSION}

By studying above research papers it is observed that

- The moment carrying capacity and shear capacity of corrosion beams may be less than that of controlled beam specimen.

- Bending moment may be decrease as compare to control beam.

- Shear capacity may be decrease compare to control beam

- Maximum load carrying capacity in three point bending test may be decrease as compare to control beam.

- Maximum torque may be decrease as compare to control beam corrosion.

\section{REFERENCES}

[1]. Thomas, A. and Hameed, A. S. (2017), “An Experimental Study On Combined Flexural And Torsional Behaviour Of RC Beams", International Research Journal of Engineering and Technology, 4(5), May 2017

[2]. Csikos, A. And Hegedus, I. (1998), "Torsion of reinforced concrete beam", 2nd int. Phd.symposium in civil engineering 1998 Budapest

[3]. Tudu, C. (2012), "Study Of Torsional Behaviour Of Rectangular Reinforced Concrete Beams Wrapped With GFRP”, Department of Civil Engineering National Institute of Technology Rourkela Odisha, India, May 2012

[4]. Rashidi, M. and Takhtfiroozeh, H.(2016), " The Evaluation of Torsional Strength in Reinforced Concrete Beam", Mechanics, Materials Science \& Engineering, December 2016

[5]. Aryanto, A. \& Shinohara, Y.(2012), "Bond Behavior between Steel and Concrete in Low Level Corrosion of Reinforcing Steel 
[6]. Chaitanya, N. and Krishna, N.(2014), "An Experimental Study of Flexural Strength of Reinforced Concrete Beam Due To Corrosion", IOSR Journal of Mechanical and Civil Engineering, 11(4), 98-109

[7]. Rahal, K. N.(2011)" Torsional strength of reinforced concrete beams", Canadian Journal of Civil Engineering, Vol. 27

[8]. Shetty, A., Venkataramana, K. and Narayan, K. S. (2014), " Effect of corrosion on flexural bond strength", J. Electrochem. Sci. Eng., 4(3) (2014), 123-134

[9]. El-Sayed, A. K., Hussain, R. R. and Shuraim, A. B.(2016) "Effect of stirrup corrosion on the shear strength of reinforced concrete short beams", Journal of Civil Engineering and Management, 22(4), 491-499

[10]. Ahmad, S.(2009) "Techniques for inducing accelerated corrosion of steel in concrete", The Arabian Journal for Science and Engineering, 34(3C)

[11]. Ashutosh Gupta(2014)"Monitoringof ReinforcedConcreteunder accelerated corrosion" Material Science and Engineering, Volume 8.

[12]. P. R. Wankhede, V. A. Fulari, Effect of Fly ASH on Properties of Concrete. IJETAE (2014) vol. 4, 284-289.

\section{Cite this article as :}

Abhinav Chouhan, Prof. Nikhil Pitale, " Review on Effect of Corrosion on Flexure, Shear and Torsional Strength of Reinforced Concrete Beam", International Journal of Scientific Research in Science and Technology(IJSRST), Print ISSN : 2395-6011, Online ISSN : 2395-602X, Volume 7, Issue 3, pp.87-91, MayJune-2020. Available at doi : https://doi.org/10.32628/IJSRST207317 Journal URL : http://ijsrst.com/IJSRST207317 